\title{
Plasmin Is Essential in Preventing Periodontitis in Mice
}

\author{
Rima Sulniute, ${ }^{*}$ Tomas Lindh, ${ }^{+\dagger}$ \\ Malgorzata Wilczynska, ${ }^{*}$ Jinan $\mathrm{Li}^{,}{ }^{*}$ and Tor $\mathrm{Ny}^{*}$ \\ From the Departments of Medical Biochemistry and Biophysics* \\ and Odontology/Prosthetic Dentistry, ${ }^{\dagger}$ Umeå University, Umeå, \\ Sweden
}

Periodontitis involves bacterial infection, inflammation of the periodontium, degradation of gum tissue, and alveolar bone resorption, which eventually leads to loss of teeth. To study the role of the broad-spectrum protease plasmin in periodontitis, we examined the oral health of plasminogen (Plg)-deficient mice. In wild-type mice, the periodontium was unaffected at all time points studied; in Plg-deficient mice, periodontitis progressed rapidly, within 20 weeks. Morphological study results of Plg-deficient mice revealed detachment of gingival tissue, resorption of the cementum layer, formation of necrotic tissue, and severe alveolar bone degradation. IHC staining showed massive infiltration of neutrophils in the periodontal tissues. Interestingly, doubly deficient mice, lacking both tissue- and urokinase-type plasminogen activators, developed periodontal disease similar to that in Plg-deficient mice; however, mice lacking only tissueor urokinase-type plasminogen activator remained healthy. Supplementation by injection of Plg-deficient mice with human plasminogen for 10 days led to necrotic tissue absorption, inflammation subsidence, and full regeneration of gum tissues. Notably, there was also partial regrowth of degraded alveolar bone. Taken together, our results show that plasminogen is essential for the maintenance of a healthy periodontium and plays an important role in combating the spontaneous development of chronic periodontitis. Moreover, reversal to healthy status after supplementation of Plg-deficient mice with plasminogen suggests the possibility of using plasminogen for therapy of periodontal diseases. (Am J Pathol 2011, 179:819-828; DOI: 10.1016/j.ajpath.2011.05.003)

Periodontal diseases comprise all of the diseases that affect one or more periodontal tissues. Most periodontal diseases are inflammatory diseases, and, depending on severity, they can be broadly divided into gingivitis and periodontitis. ${ }^{1}$ Gingivitis is mild reversible inflammation of the gums caused by bacterial plaque that accumulates on teeth at the gingival margin. Gingivitis affects $>80 \%$ of the adult population in the United States and is regarded as one of the most common human diseases. ${ }^{2}$ In some patients, gingivitis develops into periodontitis (ie, a severe and chronic inflammatory disease affecting tissues that support and anchor the teeth, such as alveolar bone, periodontal ligament, and cementum of the root). The destruction of the tooth-supporting periodontium eventually leads to loss of teeth. Periodontitis affects approximately $30 \%$ to $40 \%$ of adults in Europe and the United States, ${ }^{3,4}$ and the tissue destruction caused by periodontitis is generally regarded to be irreversible.

Periodontal diseases are caused by an imbalance in interplay between biofilm-forming bacteria on the tooth surface and the host immune response. ${ }^{1}$ Invading bacteria may induce tissue damage by releasing compounds, such as lipopolysaccharides, that have a profound effect on many cell types, including fibroblasts, osteoblasts, and osteoclasts. ${ }^{5,6}$ In addition, lipopolysaccharides activate macrophages to release proinflammatory factors, such as tumor necrosis factor- $\alpha$ and ILs (IL-1, IL-6, and IL-8). ${ }^{7,8}$ However, the major cause of the bacterially induced destruction of periodontal tissue is activation of host inflammatory cells. One of the first events to occur during bacterially induced periodontal inflammation is accumulation of neutrophils in soft periodontal tissues. Neutrophils eliminate bacteria by phagocytosis and degranulation. However, some periodontopathogenic bacteria can evade the phagocytosis, resulting in continuous accumulation and degranulation of new neutrophils. Hydrolytic enzymes released from these neutrophils then cause irreversible damage to the gums, alveolar bone, cementum, and dentin, eventually leading to tooth loss. ${ }^{9,10}$

Plasminogen (PIg) is an 88-kDa proenzyme that is synthesized mainly in the liver and secreted into the blood, where it circulates at a concentration of $2 \mu \mathrm{mol} / \mathrm{L}$. A considerable amount of Plg has also been found in the

Supported by the Swedish Research Council and the Medical Faculty of Umeå University.

Accepted for publication May 2, 2011.

Disclosures: T.L., J.L., and T.N. have applied for a patent to use plasminogen for treatment of periodontal diseases.

Address reprint requests to Tor Ny, Ph.D., Department of Medical Biochemistry and Biophysics, Umeå University, SE-901 87 Umeå, Sweden. E-mail: tor.ny@medchem.umu.se. 
extracellular matrix $(\mathrm{ECM}) .{ }^{11} \mathrm{Plg}$ is the key component of the plasminogen activator (PA) system. It can be activated through a single proteolytic cleavage to become the active broad-spectrum serine protease plasmin. The activation is performed by either of two physiological PAs: tissue-type PA (tPA) or urokinase-type PA (UPA). Because of its high affinity for fibrin, plasmin was first regarded as a key enzyme in removing fibrin clots and preventing pathological blood clot formation. ${ }^{12}$ However, it is known that plasmin also plays an important role in ECM remodeling through its ability to directly degrade ECM components, such as laminin, fibronectin, and proteoglycans, ${ }^{13-15}$ and indirectly activate matrix metalloproteinases. ${ }^{16-18}$ Many cells have various types of cell surface receptors for Plg, and plasmin activity generated on the cell surface plays a role for the migration of certain cells. ${ }^{19,20}$ Thus, plasmin is important for processes that require tissue remodeling, such as angiogenesis, metastasis, wound healing, and liver regeneration. ${ }^{13,14,20-22}$ In infectious diseases, Plg may play a dual role. On one hand, Plg is used by some bacteria to invade the host ${ }^{19,23,24}$; on the other hand, plasmin may be important for host defense against infection. ${ }^{19,25,26}$ The processes previously mentioned, in which Plg plays an important role, resemble the processes involved in periodontitis. Therefore, it would be interesting to investigate the role of $\mathrm{Plg}$ in periodontitis.

Clinical Plg mutations have been reported in patients with ligneous gingivitis/periodontitis, which is a rare genetic periodontal disease with gingival enlargement and periodontal breakdown. ${ }^{27-30}$ In humans, inherited Plg mutations are divided into two types: type 1 (hypoplasminogenemia), in which the level of immunoreactive Plg is reduced in parallel with its functional activity; and type 2 (dysplasminogenemia), in which the level of immunoreactive Plg is normal (or slightly reduced) and the specific functional Plg activity is markedly reduced. ${ }^{31}$ Interestingly, patients with ligneous gingivitis/periodontitis are reported to have type 1 Plg deficiency. Recently, Klammt et $\mathrm{a}^{32}$ reported 23 new cases of severe hypoplasminogenemia, three of which were caused by novel mutations in the Plg gene. Although many individual cases have been reported, the lack of experimental models has made it difficult to dissect the exact molecular mechanisms behind pathogenesis of ligneous periodontitis.

Herein, we showed that Plg-deficient mice spontaneously develop severe periodontitis that resembles the human disease. More important, supplementation of Plgdeficient mice with Plg for 10 days resulted in complete elimination of inflammation, regeneration of soft periodontal tissues, and partial regrowth of alveolar bone. This makes Plg an attractive potential tool for treatment of periodontal diseases in humans.

\section{Materials and Methods}

\section{Animals}

Plg-deficient mice ${ }^{33}$ were backcrossed for 10 generations with mice that had a C57BL/6 genetic background. To generate mice for experiments, Plg-heterozygous mice were intercrossed; and the wild-type, heterozygous, and Plg-deficient progeny were studied. The genotype of these mice was determined by measuring plasma levels of plasminogen, as previously described. ${ }^{34}$ Mice deficient in IPA and UPA were backcrossed for 10 generations with C57BL/6 mice. ${ }^{35}$ Then, UPA and tPA heterozygous mice were intercrossed to generate the tPA/uPA doubly deficient mice. The genotype of these mice was determined by PCR analysis, as previously described. ${ }^{36}$ The mice were kept on a 12-hour light/ 12-hour dark cycle and were fed standard chow and water ad libitum. All animal experiments were approved by the Regional Ethical Review Board of Umeå University, Umeå, Sweden.

\section{Tissue Preparation and Morphological Staining}

At the end of individual experiments, mice of both sexes were sacrificed by decapitation. Lower jaws were dissected free from surrounding soft tissues and transferred to a phosphate-buffered $4 \%$ paraformaldehyde solution for 24 hours at $4^{\circ} \mathrm{C}$. Afterward, the jaws were decalcified in 10\% EDTA for 3 weeks. Decalcified jaw samples were embedded in paraffin, sectioned to obtain 5- $\mu \mathrm{m}$-thick slices, mounted on slides, stained with fast green-safranin $\mathrm{O}$ (ie, cartilage, cementum, and epithelium, orange-red; and bone and dentin, blue), and counterstained with hematoxylin (Histolab Products AB, Gothenburg, Sweden).

\section{IHC Staining of Neutrophils and Fibrin}

Tissue sections (5- $\mu \mathrm{m}$ thick) were deparaffinized in xylene and hydrated through a series of graded ethanol-water dilutions. The sections were then washed with PBS, blocked with goat serum (Rat ABC Staining System; Santa Cruz Biotechnology, Santa Cruz, CA), and incubated with rat monoclonal antibodies to mouse lymphocyte antigen G6 (Ly-6G, 1:250; eBioscience, San Diego, CA) or goat antiserum to mouse fibrinogen (Nordic Immunology, Tilburg, the Netherlands). Primary antibodies were detected with biotinylated anti-rat antibodies (Rat ABC Staining System, Santa Cruz, CA) and anti-goat antibodies (ABC Staining System; Santa Cruz Biotechnology). Diaminobenzidine substrate (Vector Laboratories, Peterborough, UK) was used for visualization. To control nonspecific staining, tissue sections were treated as previously noted, but the anti-Ly-6G primary antibody was omitted. Finally, the sections were counterstained with hematoxylin and the preparations were mounted with xylene-based Pertex mounting medium (Histolab Products $\mathrm{AB}$ ). Images were obtained using a Leica DML microscope with a Leica D300F camera (Leica Microsystems $\mathrm{GmbH}$, Wetzlar, Germany).

\section{Quantification of Necrotic Tissue Area and Level of Alveolar Bone}

Quantitative measurements of necrotic tissue and alveolar bone level were performed blindly on 100-fold magnified pictures of sections stained with safranin $\mathrm{O}$, using 
Table 1. Number of Mice Analyzed Morphologically in Each Age Group

\begin{tabular}{ccc}
\hline $\begin{array}{c}\text { Age group } \\
\text { (weeks) }\end{array}$ & $\begin{array}{c}\text { No. of Plg-deficient } \\
\text { mice }\end{array}$ & $\begin{array}{c}\text { No. of wild-type } \\
\text { mice }\end{array}$ \\
\hline $4-8$ & 28 & 15 \\
$9-12$ & 13 & 9 \\
$13-16$ & 16 & 13 \\
$17-20$ & 13 & 12 \\
\hline
\end{tabular}

AxioVision software version 4.2 (Carl Zeiss Microlmaging $\mathrm{GmbH}$, Göttingen, Germany). Alveolar bone degradation and the associated area of necrotic tissue were monitored between molars 1 and 2. The area on tissue sections where cells were morphologically indistinguishable was regarded as necrotic tissue and measured (in $\mu \mathrm{m}^{2}$ ). The alveolar bone level was defined by measuring the distance between the cementoenamel junction (CEJ) and the alveolar bone crest. Data were analyzed by two-tailed Student's $t$-test, and differences were considered significant at $P<0.05$.

\section{Reconstitution of Plasminogen in Plg-Deficient Mice}

Plg-deficient mice were randomly assigned to four experimental groups. Two groups, consisting of five mice aged 9 to 12 weeks and four mice aged 17 to 20 weeks, were injected i.v. daily with $1 \mathrm{mg}$ of human plasminogen (Gluplasminogen; Omnio AB, Umeå, Sweden) in $100 \mu \mathrm{L}$ of PBS. In parallel, two control groups, five mice aged 9 to 12 weeks and four mice aged 17 to 20 weeks, were injected with $100 \mu \mathrm{L}$ of PBS. All of the injections were performed i.v. on a daily basis for 10 days.

\section{Alkaline Phosphatase Staining}

Alkaline phosphatase staining was performed on paraffin-embedded tissue sections following a previously described method. ${ }^{37}$ Briefly, dissected jaws were fixed for 24 hours in $2 \%$ paraformaldehyde containing $0.075 \mathrm{~mol} / \mathrm{L}$ lysine and $0.01 \mathrm{~mol} / \mathrm{L}$ sodium periodate solution $(\mathrm{pH} 7.4)$. After fixation, the specimens were washed for 12 hours with increasing concentrations of glycerol in PBS (stepwise up to $15 \%$ ). The tissues were then decalcified in 0.4 mol/L EDTA solution ( $\mathrm{pH}$ 7.3) containing $0.3 \mathrm{~mol} / \mathrm{L} \mathrm{NaOH}$ and $15 \%$ glycerol for 2 weeks and further washed to remove EDTA and glycerol. Finally, the jaw samples were embedded in paraffin, sectioned to 5 - $\mu$ m-thick slices, mounted on slides, deparaffinized, hydrated through a graded ethanol series, and preincubated in 1\% magnesium chloride overnight. The sections were then incubated with alkaline phosphatase substrate solution (Fast Red TR/Naphthol AS-MX; Sigma-Aldrich, St. Louis, MO) for 1 hour and counterstained with methyl green (Vector Laboratories, Burlingame, CA).

\section{Results}

\section{Plg-Deficient Mice Spontaneously Develop Severe Periodontitis}

To investigate the condition of oral health in wild-type and Plg-deficient mice of different ages, mice were divided into four age groups (ie, 4 to 8,9 to 12,13 to 16 , and 17 to 20 weeks) and morphological analysis of lower jaw sections was performed. The number of mice analyzed in each age group is shown in Table 1. No pathological changes were observed in periodontal tissues of wildtype mice up to the age of 20 weeks. As shown in Figure $1, A, C, E$, and $G$, there was no inflammation in gum tissue, no alveolar bone degradation, and no detachment of tissue from teeth. Plg-deficient mice showed generally healthy periodontal tissues at the age of 6 weeks (Figure 1B). However, in older mice, the formation of necrotic tissue in the gum and the degradation of bone septa were observed. This was already apparent at the age of 11 weeks (Figure 1D) and had progressed by the age of 15 weeks (Figure 1F). At the age of 20 weeks (Figure 1H), all Plg-deficient mice showed severe periodontitis: the gum tissue was detached from the teeth and had become

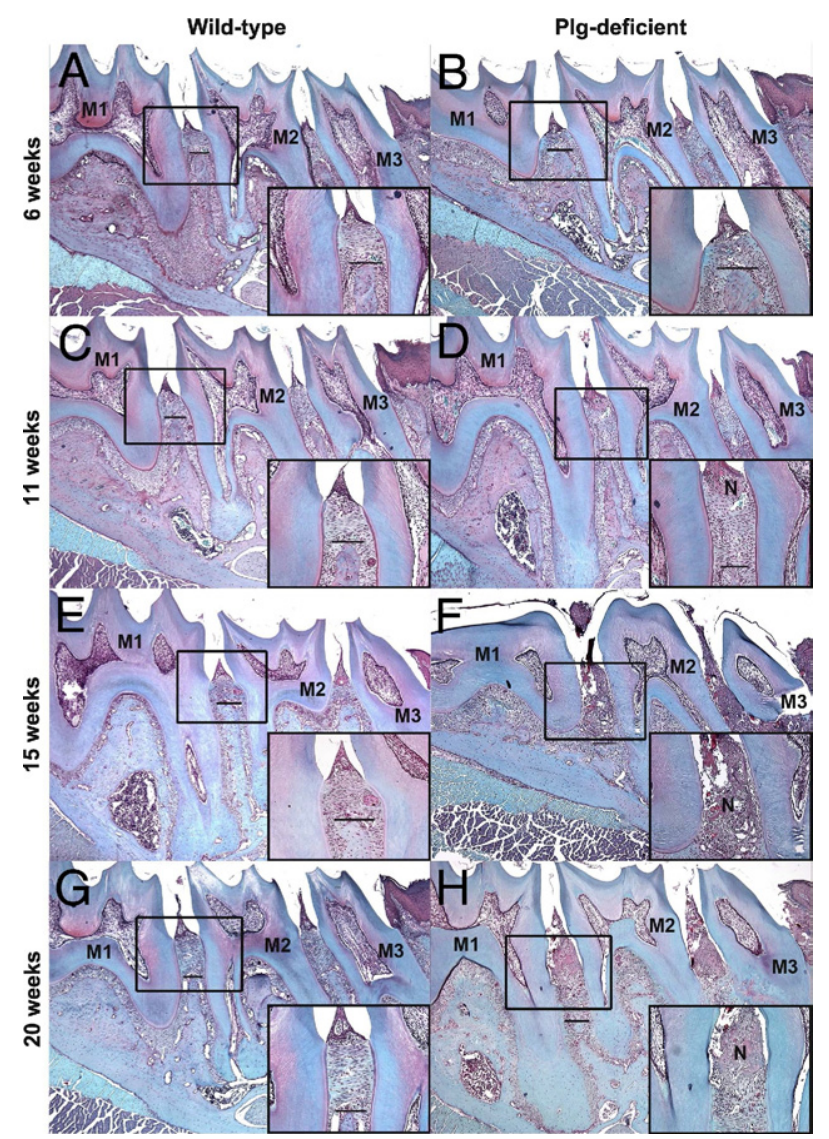

Figure 1. Plg-deficient, but not wild-type, mice spontaneously develop periodontal disease. Paraffin sections of 6-, 11-, 15-, and 20-week-old wildtype mice ( $\mathbf{A}, \mathbf{C}, \mathbf{E}$, and $\mathbf{G}$, respectively) and Plg-deficient mice $(\mathbf{B}, \mathbf{D}, \mathbf{F}$, and $\mathbf{H}$, respectively) were stained with green-safranin $O$ and counterstained with hematoxylin. $\mathrm{N}$ indicates necrotic tissue; $\mathrm{M} 1, \mathrm{M} 2$, and $\mathrm{M} 3$, molars 1, 2, and 3, respectively; and black horizontal line, alveolar bone crest. Original magnification: $\times 50(\mathbf{A}-\mathbf{H}) ; \times 200$ (insets). 

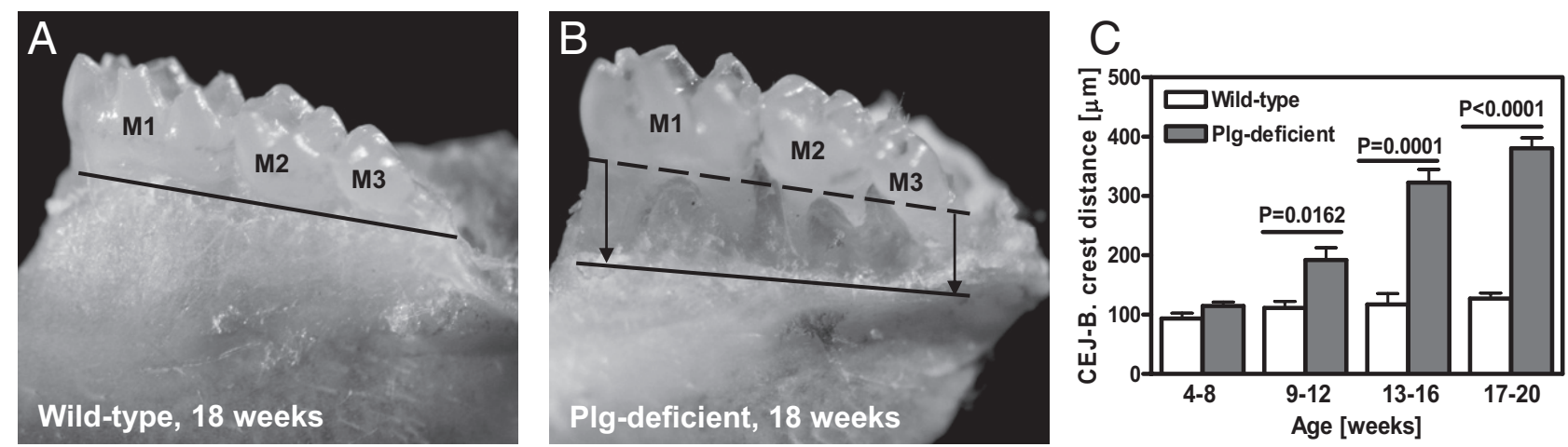

Figure 2. Plg deficiency leads to degradation of alveolar bone. Images of deflashed lower jaws of 18-week-old wild-type (A) and Plg-deficient (B) mice. The solid line marks the edge of alveolar bone in both genotypes. The dashed line in $\mathbf{B}$ indicates the presumed edge of alveolar bone under healthy conditions. Arrows indicate the resorption level of alveolar bone in a Plg-deficient mouse. M1, M2, and M3 indicate molars 1, 2, and 3, respectively. C: Quantification of alveolar bone level in wild-type and Plg-deficient mice of different ages. Alveolar bone degradation was monitored between molars 1 and 2 and is expressed as the distance between the CEJ and the alveolar bone crest (B. crest).

increasingly necrotic, the cementum layer was completely destroyed, and gingival fibers were not distinguishable.

Clinically, periodontitis in humans is characterized by the degradation of alveolar bone, which causes loose teeth and, in severe cases, loss of teeth. Figure 2 shows a comparison of alveolar bone in the lower jaws of wildtype and Plg-deficient mice at the age of 18 weeks. Although the alveolar bone in wild-type mice was intact and covered the roots of teeth (Figure 2A), the alveolar bone in Plg-deficient mice was severely degraded, exposing approximately two thirds of molar roots (Figure 2B). To quantify the alveolar bone level in wild-type and Plg-deficient mice, we measured the distance between the CEJ and the alveolar bone crest on sectioned tissue samples. As shown in Figure 2C, the level of alveolar bone crest was similar in wild-type and Plg-deficient mice in the 4- to 8-week age group. However, at the age of 9 to 12 weeks, alveolar bone was significantly lower in Plgdeficient mice than in wild-type mice; and the difference further increased with age. Taken together, these results clearly demonstrate that, in contrast to wild type mice, Plg-deficient mice spontaneously develop periodontitis that becomes more severe with age.

\section{Extensive Neutrophil Accumulation in the Periodontal Tissue of Plg-Deficient Mice during Spontaneous Development of Periodontitis}

Human periodontitis is classified as an infectious disease, and it is accompanied by massive infiltration of neutrophils into soft periodontal tissues. ${ }^{9}$ To determine whether the development of spontaneous periodontitis in Plg-deficient mice resembles human disease in this respect, we analyzed neutrophils in the periodontium of mice at the ages of 4, 11, 15, and 19 weeks (Figure 3). As shown by immunohistochemical (IHC) staining, only a few neutrophils were detected in periodontal samples from wild-type mice at all time points (Figure 3, A, C, E, and $\mathrm{G}$ ). Also, 4-week-old Plg-deficient mice did not show any difference in neutrophil staining compared with wildtype mice of the same age (Figure 3B). However, more neutrophils were detected in 11-week-old Plg-deficient mice (Figure 3D); and massive accumulation of neutrophils was seen in these mice at the ages of 15 and 19 weeks (Figure 3, $\mathrm{F}$ and $\mathrm{H}$, respectively). Most of the neutrophil-specific immunoreactivity was observed in the gum tissue between molars, which is the area where necrosis was detected. This increased infiltration and accumulation of neutrophils in the gum tissue of Plgdeficient mice suggests that the lack of expression of Plg

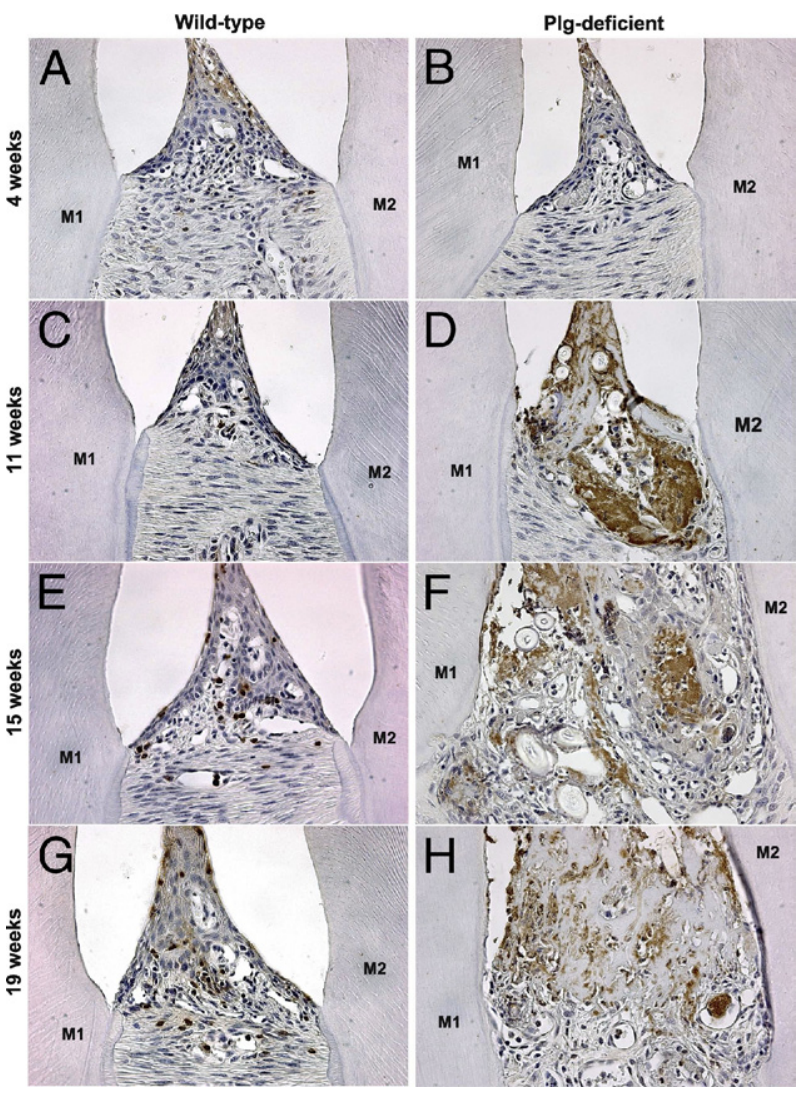

Figure 3. Neutrophil accumulation in the gums of wild-type and Plg-deficient mice. Tissue sections from the lower jaws of wild-type mice $(\mathbf{A}, \mathbf{C}, \mathbf{E}$ and $\mathbf{G}$ ) and Plg-deficient mice ( $\mathbf{B}, \mathbf{D}, \mathbf{F}$, and $\mathbf{H})$ of different ages (as indicated) were immunostained with antibodies to mouse lymphocyte antigen G6. M1 and M2 indicate molars 1 and 2, respectively. Original magnification, $\times 400$. 


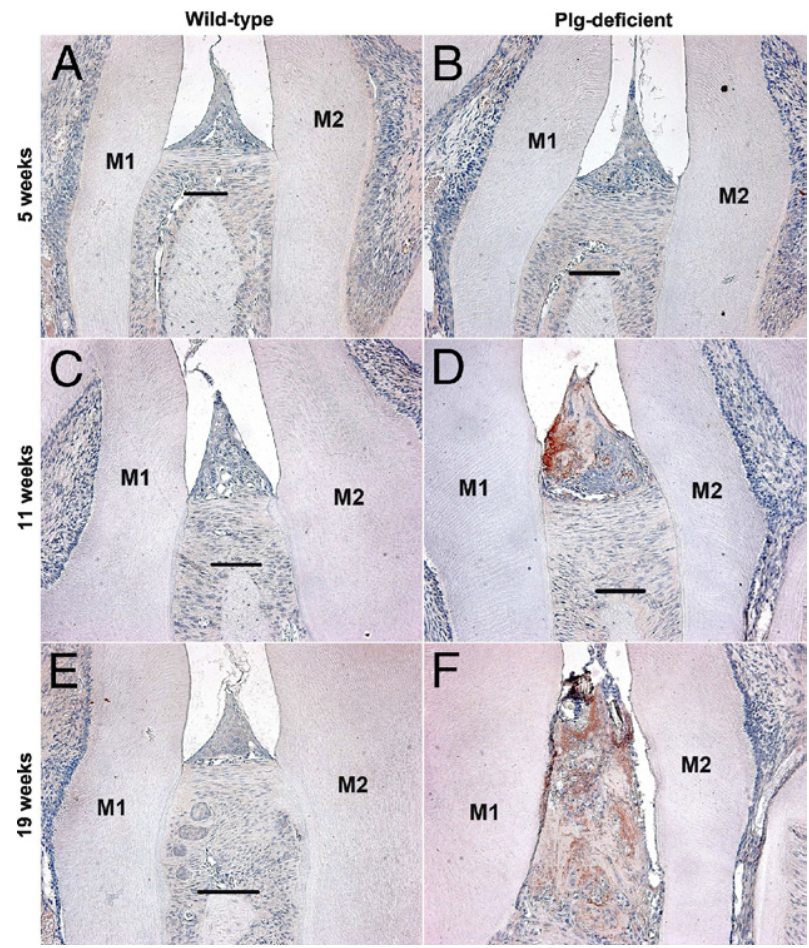

Figure 4. Fibrin accumulation in the gums of wild-type and Plg-deficient mice Tissue sections from the lower jaws of wild-type mice (A, C, and $\mathbf{E}$ ) and Plg-deficient mice (B, D, and $\mathbf{F}$ ) of different ages (as indicated) were immunostained with antibodies to mouse fibrinogen. M1 and M2 indicate molars 1 and 2 , respectively. The black horizontal line marks the alveolar bone crest. Original magnification, $\times 200$.

results in persistent and unresolved inflammation of the periodontal tissue.

\section{Fibrin Deposits in Damaged Gum Tissue of Plg-Deficient Mice}

In previous studies of Plg-deficient mice, fibrin deposits have been documented in some organs. Therefore, we performed $\mathrm{IHC}$ staining of fibrin in gum tissue of wild-type and Plg-deficient mice. There were no fibrin deposits observed in periodontal tissues of wild-type mice up to the age of 20 weeks (Figure 4, A, C, and E). Fibrin deposits were also not detected in the gums of Plg-deficient mice at the age of 4 to 5 weeks (Figure 4B). However, along with a progression of periodontal disease in Plg-deficient mice, we could detect fibrin staining, but only in areas of diseased and necrotizing gum tissue (Figure 4, D and F).

\section{tPA/uPA Doubly Deficient Mice Spontaneously Develop Severe Periodontitis}

To investigate whether the development of periodontitis in Plg-deficient mice was because of the lack of plasmin activity, we studied singly deficient mice lacking either tPA or UPA and doubly deficient mice lacking both tPA and UPA. Singly deficient mice lacking either tPA (Figure $5 A$ ) or uPA (Figure 5B) had healthy periodontal tissues at the age of 18 weeks with no sign of alveolar bone degradation (Figure 5D). However, doubly deficient mice
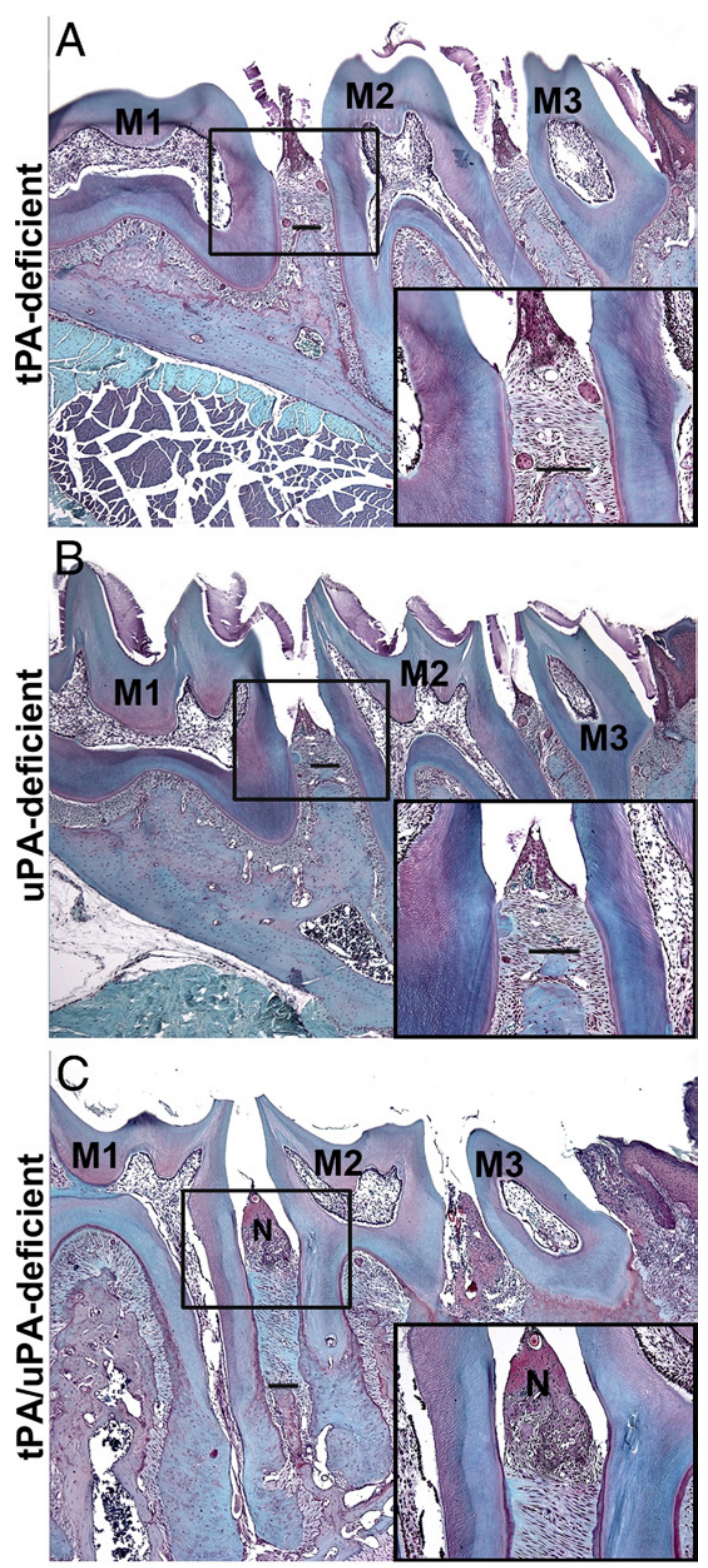

D

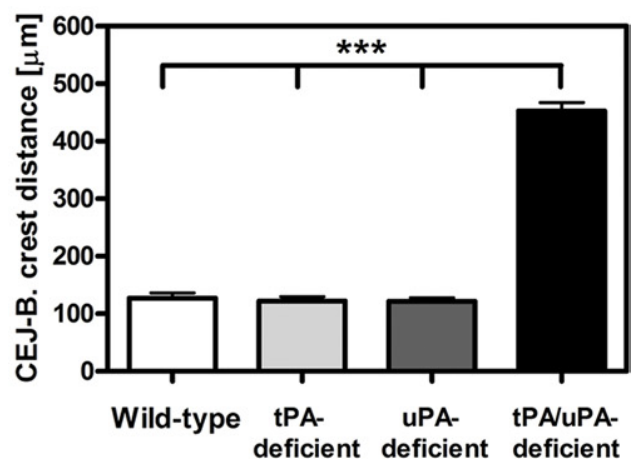

Figure 5. The tPA/uPA doubly deficient mice develop periodontal disease whereas IPA and UPA single-deficiency mice remain healthy. Representative jaw sections from 18-week-old tPA single-deficiency mice (A) and uPA single-deficiency mice $(\mathbf{B})$ and the tPA/uPA doubly deficient mice $(\mathbf{C})$ were prepared and stained as described in the legend to Figure 1. N indicates necrotic tissue; M1, M2, and M3, molars 1, 2, and 3, respectively; black horizontal line, alveolar bone crest. D: Quantification of alveolar bone levels (B, crest) in wild-type and PA-deficient mice. **: $P<0.0001$ 


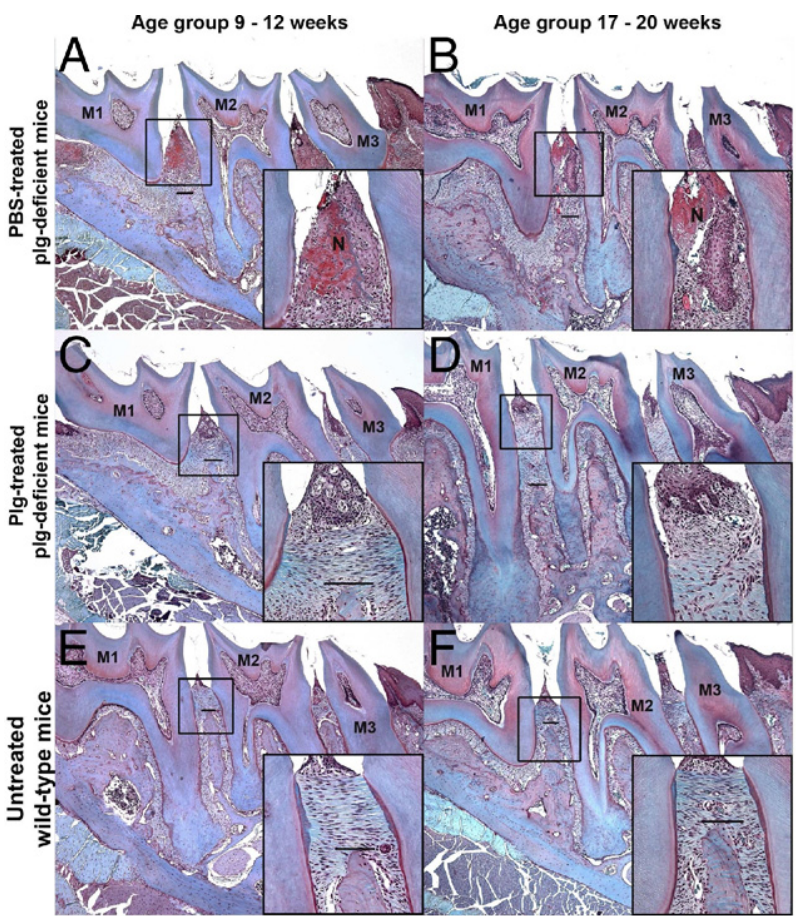

Figure 6. Plasminogen supplementation of Plg-deficient mice results in healing of periodontitis and reversion of pathological changes in soft periodontal tissues to a healthy condition. Plg-deficient mice in two age groups (as indicated) were injected i.v. with PBS (A and $\mathbf{B}$ ) or $1 \mathrm{mg}$ of human plasminogen ( $\mathbf{C}$ and $\mathbf{D})$ for 10 days. Then, jaw sections were prepared as described in the legend to Figure 1. E and F: Analogous sections of jaws from untreated wild-type mice are shown for comparison. $\mathrm{N}$ indicates necrotic tissue; M1, M2, and M3, molars 1, 2, and 3, respectively; black horizontal line, alveolar bone crest

lacking both tPA and uPA (Figure 5C) showed severe changes in the periodontium, including necrosis, detachment of gum tissue from the molars, and severe degradation of the alveolar bone. The severity of periodontal disease in the tPA/uPA doubly deficient mice was similar to that in Plg-deficient mice comparing levels of alveolar bone degradation (Figure 5D and 2C, respectively). Considering that IPA and UPA are the two major physiological PAs, these results clearly show that plasmin activity is the essential factor for maintenance of healthy periodontal tissues in mice.

\section{Systemic Supplementation of Plg-Deficient Mice with Plasminogen Cures Their Periodontal \\ Disease}

Because Plg-deficient mice spontaneously develop periodontitis that resembles the human disease, we wanted to know whether supplementation with Plg might reverse the pathological changes in the periodontium. Plg-deficient mice were divided into two groups: 9- to 12-weekold mice with early symptoms of periodontitis and 17- to 20-week-old mice with severe periodontitis. The mice in each group received supplementation daily with human Plg by i.v. injection ( $1 \mathrm{mg} / 100 \mu \mathrm{L}$ ) for 10 days or received an injection with PBS as a control. As shown in Figure 6, $A$ and $B$, the periodontium of all mice injected with PBS

had pathological changes that were typical of Plg deficiency at this age (compared with Figure 1, D and $H$, respectively). However, the periodontal tissues of all mice treated with human Plg (Figure 6, C and D) had significantly recovered. After 10 days of treatment, the periodontal tissue was generally healthy and appeared almost as healthy as in wild-type mice (Figure 6, E and F). In both age groups of Plg-deficient mice that received supplementation with $\mathrm{Plg}$, periodontal regeneration involved reappearance of fibroblasts and connective tissue and realignment of collagen structures. This resulted in the formation and reattachment of epithelium and connective tissue fibers to the surface of the root (Figure 6, C and D). In addition, necrotic tissue was significantly reduced in all mice that received supplementation with Plg (Figure 6, C and D) compared with PBS-treated animals (Figure 6, A and B). Quantification of necrotic tissue clearly showed that all of the necrotic tissue had been removed in the Plg-treated mice aged 9 to 12 weeks and that only approximately $6 \%$ of the necrotic tissue remained in the mice aged 17 to 20 weeks, relative to the status of untreated Plg-deficient mice. In contrast, the amount of necrotic tissue had increased in corresponding mice that had been given PBS treatment (Figure 7, A and B).

A Age group 9-12 weeks
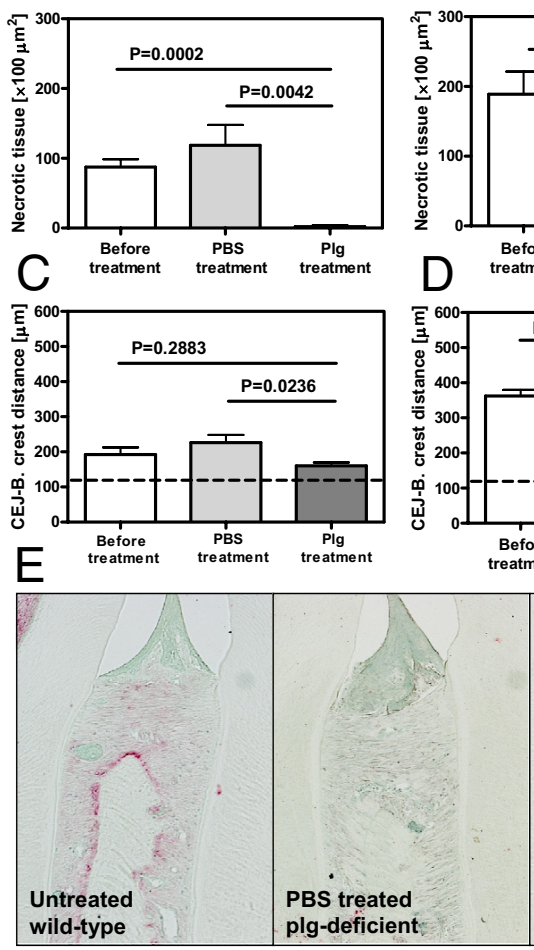

Figure 7. Plasminogen supplementation of Plg-deficient mice leads to clear ing of necrotic tissue and regrowth of alveolar bone. A and B: Quantification of necrotic tissue area in two age groups of Plg-deficient mice (as indicated) before and after supplementation with human plasminogen. The necrotic tissue area was quantified as described in the Materials and Methods section. C and D: Quantification of the alveolar bone levels in two age groups of Plg-deficient mice before and after supplementation with human plasminogen. The dotted line indicates the level of alveolar bone in wild-type mice. B. crest indicates alveolar bone crest. E: Alkaline phosphatase activity staining in jaw sections of untreated wild-type mice and Plg-deficient mice supplemented with PBS or human plasminogen. Original magnification, $\times 100$. 
Periodontitis in Plg-deficient mice was characterized by severe alveolar bone degradation. As shown in Figure 7, C and D, the distance between the CEJ and the alveolar bone crest in Plg-deficient mice of both age groups before treatment was significantly greater than for wildtype mice. PBS treatment of Plg-deficient mice resulted in further loss of alveolar bone: by approximately $20 \%$ and $7 \%$ in mice in the 9- to 12-week and the 17- to 20-week age groups, respectively. However, the distance between the CEJ and the alveolar bone crest in Plg-treated mice decreased by approximately $17 \%$ in 9- to 12 -weekold mice and $25 \%$ in 17- to 20-week-old mice (Figure 7, C and $\mathrm{D}$, respectively), indicating that there was significant regrowth of alveolar bone in the plasminogen-treated mice. To confirm this finding, we performed staining for alkaline phosphatase activity, an enzyme that is known to be expressed by osteoblasts at the site of bone formation. As expected, there was no alkaline phosphatase activity at the alveolar bone crest in the PBS-treated mice (Figure 7E). However, the mice that received supplementation with Plg showed clear staining for alkaline phosphatase at the surface of alveolar bone, which resembled that in wild-type mice (Figure 7E). This indicates that Plg supplementation of Plg-deficient mice leads to the activation of osteoblasts in alveolar bone.

\section{Discussion}

People who experience Plg deficiency have a tendency to develop ligneous periodontitis. ${ }^{27,28}$ However, to our knowledge, the possible role that Plg might play in the maintenance of periodontal health had not been studied. Herein, we showed that Plg-deficient mice spontaneously develop periodontitis that progresses with age. The development of periodontitis in these mice resembles that in humans and is characterized by the formation of necrotic tissue, the influx of neutrophils, and the detachment of gingival tissue from the teeth, followed by severe degradation of alveolar bone. This contrasts with the situation in wild-type mice, which have a healthy periodontium irrespective of age. Therefore, Plg-deficient mice can be used as a new rodent model to study periodontitis. More important, systemic supplementation of Plg-deficient mice with human Plg for 10 days resulted in almost complete regeneration of soft periodontal tissues and significant regrowth of alveolar bone. These results indicate that Plg has an essential role in protecting against spontaneous development of chronic periodontal disease. Our results also suggest that Plg treatment may be a new therapeutic strategy to treat infectious periodontitis.

In previous studies, doubly deficient mice lacking both IPA and UPA show much more severe phenotypes than mice with a IPA or UPA single deficiency in liver injury ${ }^{38}$ and wound healing ${ }^{39}$ models. Herein, we showed that Plg-deficient mice and tPA/uPA doubly deficient mutant mice spontaneously develop periodontitis with a severity similar to that seen in Plg-deficient mice, whereas tPA and UPA single-deficiency mice had a normal and healthy periodontium (Figure 5). Because IPA and UPA are the major physiological activators of Plg, our results indicate that active plasmin is essential for the prevention of periodontitis and that lack of plasmin activity results in the development of the disease. A likely explanation is that in the single-deficient mice, the remaining Plg activator could activate plasmin to the level that is required for prevention of periodontal disease.

Periodontal inflammation in humans is initiated by bacterial colonization and expansion at the site of attachment, between the gum tissue and the tooth, which stimulates the host defense and migration of inflammatory cells into periodontal tissues. ${ }^{9,10}$ Plg-deficient mice are more susceptible to systemic infection and bacterially induced arthritis than wild-type mice, and supplementation with Plg improves the bacterial killing ability. ${ }^{26}$ Therefore, we estimated the number of bacteria in extracts prepared from homogenized mandibles from wild-type and Plg-deficient mice by plating on blood agar plates (data not shown). Our results revealed that the number of colony-forming units in extracts from Plg-deficient mice was approximately 100-fold higher compared with wildtype mice. We also treated Plg-deficient mice with amoxicillin by supplementing drinking water from birth until the mice were examined. ${ }^{40}$ However, periodontium degradation in the amoxicillin-treated mice was comparable to nontreated Plg-deficient mice, suggesting that the amoxicillin treatment did not rescue the Plg-deficient mice from the disease. Future more extensive studies on mice bred in a pathogen-free environment will elucidate whether periodontitis in this mouse model is because of periopathogens or related to defects in the immune defense.

Previous studies ${ }^{41}$ of Plg-deficient mice have revealed fibrin deposits in some tissues. However, in this study, we could only detect fibrin deposits in already diseased gum tissue (Figure 4). Thus far, the molecular mechanism behind the initiation of periodontal disease in Plg-deficient mice has not been analyzed in detail. Therefore, it cannot be excluded that fibrin may play a role in the development of the disease. One possibility is that fibrin, in synergy with bacteria, triggers inflammation and thereby contributes to the development of periodontal disease. The fact that only $32 \%$ of patients who have type $1 \mathrm{Plg}$ deficiency develop ligneous gingivitis/periodontitis suggests that external triggers, such as infections and trauma, may play a role in the development of disease. ${ }^{29,32}$ Numerous ligneous gingivitis/periodontitis case studies ${ }^{42-45}$ in humans have shown intense infiltration of inflammatory cells, fibrin deposits, irregularly downward epithelium proliferation, and alveolar bone degradation. Unfortunately, bacterial determinations were not performed in those patients.

Plg-deficient mice show persistent inflammation and neutrophil migration to the infected gum tissue. Despite the presence of neutrophils in these mice, there was no or little tissue debridement leading to accumulation of necrotic tissue and, finally, to development of periodontitis (Figures 1 and 3). However, the administration of Plg to these mice resulted in quenching of inflammation and removal of necrotic tissue from the periodontal area (Figures 6 and 7). These results support the idea that Plg has a role in activation of the host defense system against bacterial invasion and suggest that the phagocytic func- 
tion of neutrophils may be impaired in the absence of $\mathrm{Plg} .{ }^{46} \mathrm{In}$ line with the present findings, a previous in vivo study, ${ }^{26}$ performed in wild-type and Plg-deficient mice using a Staphylococcus aureus-induced arthritis model, revealed protective roles of Plg. The importance of leukocyte activity for the prevention of periodontitis is also supported by studies ${ }^{47,48}$ showing that impaired leukocyte function in mice and humans that are deficient in L-selectin and in humans with leukocyte adhesion deficiency 2 correlate with an early onset of progressive periodontitis.

The regeneration of periodontal tissues involves complex interactions between different cell types, the ECM, and local mediators, such as growth factors and cytokines. There are many conventional treatments that are used for periodontitis, but few of them result in complete regeneration of periodontal soft tissue. ${ }^{49}$ As shown herein, the administration of Plg to Plg-deficient mice led to full regeneration of soft periodontal tissues. This involved removal of necrotic tissue and formation of new periodontal ligament fibers connecting epithelial and connective tissues to the root of the tooth (Figure 6). Similar to what has been described herein, Plg-driven tissue remodeling and healing were observed when Plgdeficient mice with bacterially induced arthritis received supplementation with Plg. ${ }^{26}$ In that case, Plg supplementation resulted in removal of necrotic tissue and bacteria, regeneration of cartilage, and, finally, restoration of healthy morphological features in the knee joint. It is likely that the ability of plasmin to degrade ECM components directly or through activation of pro-matrix metalloproteinases plays an important role in both processes. ${ }^{18,50}$

There appears to be no single therapeutic treatment that can reverse all pathological changes in soft and bone periodontal tissues. One of the major problems with treatment of periodontitis is the regeneration of alveolar bone. Most often, the healing of the periodontium is accompanied by rapid growth of epithelial cells that cover the root surface. This prevents the repopulation of osteogenic fibroblasts and osteoblasts on wounded periodontal bone and, therefore, prevents bone regeneration. ${ }^{51-55}$ In fact, few treatments of periodontitis stimulate the regrowth of alveolar bone to any great extent; and periodontal bone regeneration is still regarded to be more or less an illusion. ${ }^{49}$ The most promising methods, such as guided tissue regeneration, enamel matrix protein treatment, and use of growth factors, are expensive and technically demanding. Surprisingly, in this study, we found that simple 10-day systemic supplementation of Plg-deficient mice with plasminogen resulted in the appearance of active osteoblasts and regrowth of alveolar bone by up to $25 \%$ (Figure 7 ).

The formation/regeneration of bone involves three different phases: resorption, bone formation, and mineralization. During the resorption phase, bone matrix at the site of the wound is degraded to prepare attachment sites for bone-building cells. Bone matrix degradation also results in release and activation of growth factors and chemoattractants that drive the adhesion and proliferation of osteoblasts during the regeneration process. ${ }^{56}$ Plasmin activity is important for the resorption phase, by degrading noncollagenous components of bone matrix. ${ }^{57}$ Several studies ${ }^{14,58,59}$ have also shown that the PA system has the ability to activate pro-matrix metalloproteinases and that plasmin, in concert with matrix metalloproteinases, directly degrades components of the ECM, including fibronectin, collagen, proteoglycans, and laminin. However, we cannot exclude the possibility that plasmin also participates in bone formation. Plasmin can activate transforming growth factor $\beta$ and release insulinlike growth factor from bone matrix, which may then independently stimulate osteoblast proliferation and activity. ${ }^{60,61}$ In vitro, plasmin can cleave osteocalcin, ${ }^{62}$ which is a bone-specific protein important for recruitment of osteoclasts and osteoblasts. ${ }^{63,64}$ Osteoblasts express tPA, uPA, PA inhibitor 1 , and a cellular receptor for UPA. ${ }^{65}$ Interestingly, the bone matrix of tPA/uPA doubly deficient mice contains elevated amounts of osteocalcin, fibronectin, and proteoglycans; and shows increased bone formation. ${ }^{57}$ However, these studies were performed in mice at the age of 2 to 7 days. It remains unknown whether bone formation may be impaired in adult animals. Based on our results, Plg may have positive effects on bone formation, especially in pathological conditions such as periodontitis.

To our knowledge, there has been no established treatment for humans with ligneous periodontitis; these patients do not respond to surgical treatments or to application of heparin combined with antibiotics. ${ }^{66}$ Surgical removal of gingival masses, in combination with warfarin and antibiotic treatment, was successfully used in one of the ligneous gingivitis cases. ${ }^{67}$ Our current data show that plasminogen supplementation in Plg-deficient mice can heal periodontitis, and previously reported data ${ }^{68,69}$ on effective treatment of ligneous conjunctivitis with topical Plg strongly indicate that Plg treatment in ligneous gingivitis/periodontitis in humans could be a potential therapeutic application.

Taken together, our results have shown that plasmin plays a critical role in maintaining healthy periodontal tissues and that the absence of plasmin activity leads to periodontitis. Plg-deficient mice spontaneously develop periodontitis with pathological features similar to that in humans. Therefore, this mouse model can be used as a new model for studies of periodontal disease. Supplementation of diseased Plg-deficient mice with plasminogen leads to clearing of necrotic tissue, full regeneration of soft periodontal tissues, and significant regrowth of alveolar bone, suggesting that plasminogen may be an effective future therapy for the treatment of periodontitis in humans.

\section{References}

1. Pihlstrom BL, Michalowicz BS, Johnson NW: Periodontal diseases Lancet 2005, 366:1809-1820

2. Albandar JM, Rams TE: Global epidemiology of periodontal diseases: an overview. Periodontol 2000 2002, 29:7-10

3. Sheiham A, Netuveli GS: Periodontal diseases in Europe. Periodontol 2000 2002, 29:104-121

4. Albandar JM: Periodontal diseases in North America. Periodontol 2000 2002, 29:31-69 
5. Nair SP, Meghji S, Wilson M, Reddi K, White P, Henderson B: Bacterially induced bone destruction: mechanisms and misconceptions. Infect Immun 1996, 64:2371-2380

6. Liu J, Wang S, Zhang P, Said-Al-Naief N, Michalek SM, Feng X: Molecular mechanism of the bifunctional role of lipopolysaccharide in osteoclastogenesis. J Biol Chem 2009, 284:12512-12523

7. Fujihara M, Muroi M, Tanamoto K, Suzuki T, Azuma H, Ikeda H: Molecular mechanisms of macrophage activation and deactivation by lipopolysaccharide: roles of the receptor complex. Pharmacol Ther 2003, 100:171-194

8. Martinez FO, Sica A, Mantovani A, Locati M: Macrophage activation and polarization. Front Biosci 2008, 13:453-461

9. Clark WB, Löe $\mathrm{H}$ : Mechanisms of initiation and progression of periodontal disease. Periodontol 2000 1993, 2:72-82

10. Deas DE, Mackey SA, McDonnell HT: Systemic disease and periodontitis: manifestations of neutrophil dysfunction. Periodontol 2000 2003, 32:82-104

11. Zhang L, Seiffert D, Fowler BJ, Jenkins GR, Thinnes TC, Loskutoff DJ, Parmer RJ, Miles LA: Plasminogen has a broad extrahepatic distribution. Thromb Haemost 2002, 87:493-501

12. Arnout J, Hoylaerts MF, Lijnen HR: Haemostasis. Handb Exp Pharmacol 2006, (Pt 2):1-41

13. Collen D: Ham-Wasserman lecture: role of the plasminogen system in fibrin-homeostasis and tissue remodeling. Hematology Am Soc Hematol Educ Program 2001, 1-91

14. Mignatti $P$, Rifkin DB: Biology and biochemistry of proteinases in tumor invasion. Physiol Rev 1993, 73:161-195

15. Rifkin DB, Mazzieri R, Munger JS, Noguera I, Sung J: Proteolytic control of growth factor availability. Apmis 1999, 107:80-85

16. Santala A, Saarinen J, Kovanen P, Kuusela P: Activation of interstitial collagenase, MMP-1, by Staphylococcus aureus cells having surface-bound plasmin: a novel role of plasminogen receptors of bacteria. FEBS Lett 1999, 461:153-156

17. Murphy G, Ward R, Gavrilovic J, Atkinson S: Physiological mechanisms for metalloproteinase activation. Matrix Suppl 1992, 1:224-230

18. Carmeliet $P$, Moons L, Lijnen R, Baes M, Lemaitre V, Tipping P, Drew A, Eeckhout Y, Shapiro S, Lupu F, Collen D: Urokinase-generated plasmin activates matrix metalloproteinases during aneurysm formation. Nat Genet 1997, 17:439-444

19. Syrovets T, Simmet T: Novel aspects and new roles for the serine protease plasmin. Cell Mol Life Sci 2004, 61:873-885

20. Ploplis VA, French EL, Carmeliet P, Collen D, Plow EF: Plasminogen deficiency differentially affects recruitment of inflammatory cell populations in mice. Blood 1998, 91:2005-2009

21. Shanmukhappa K, Matte U, Degen JL, Bezerra JA: Plasmin-mediated proteolysis is required for hepatocyte growth factor activation during liver repair. J Biol Chem 2009, 284:12917-12923

22. Romer J, Bugge TH, Pyke C, Lund LR, Flick MJ, Degen JL, Dano K Impaired wound healing in mice with a disrupted plasminogen gene. Nat Med 1996, 2:287-292

23. Broder CC, Lottenberg R, von Mering GO, Johnston KH, Boyle MD Isolation of a prokaryotic plasmin receptor: relationship to a plasminogen activator produced by the same micro-organism. J Biol Chem 1991, 266:4922-4928

24. Berge A, Sjobring U: PAM, a novel plasminogen-binding protein from Streptococcus pyogenes. J Biol Chem 1993, 268:25417-25424

25. Brandtzaeg $P$, Joo GB, Brusletto B, Kierulf P: Plasminogen activator inhibitor 1 and 2, alpha-2-antiplasmin, plasminogen, and endotoxin levels in systemic meningococcal disease. Thromb Res 1990, 57: 271-278

26. Guo Y, Li J, Hagstrom E, Ny T: Protective effects of plasmin(ogen) in a mouse model of Staphylococcus aureus-induced arthritis. Arthritis Rheum 2008, 58:764-772

27. Gunhan O, Gunhan M, Berker E, Gurgan CA, Yildirim H: Destructive membranous periodontal disease (Ligneous periodontitis). J Periodontol 1999, 70:919-925

28. Scully C, Gokbuget AY, Allen C, Bagan JV, Efeoglu A, Erseven G, Flaitz C, Cintan S, Hodgson T, Porter SR, Speight P: Oral lesions indicative of plasminogen deficiency (hypoplasminogenemia). Oral Surg Oral Med Oral Pathol Oral Radiol Endod 2001, 91:334-337

29. Tefs K, Gueorguieva M, Klammt J, Allen CM, Aktas D, Anlar FY, Aydogdu SD, Brown D, Ciftci E, Contarini P, Dempfle CE, Dostalek M, Eisert S, Gokbuget A, Gunhan O, Hidayat AA. Hugle B, Isikoglu M, Irkec M, Joss SK, Klebe S, Kneppo C, Kurtulus I, Mehta RP, Ornek K,
Schneppenheim R, Seregard S, Sweeney E, Turtschi S, Veres G, Zeitler P, Ziegler M, Schuster V: Molecular and clinical spectrum of type I plasminogen deficiency: a series of 50 patients. Blood 2006 108:3021-3026

30. Baltacioglu E, Akalin FA, Topaloglu E, Sukuroglu E, Cobanoglu U: Ligneous periodontitis and gingival antioxidant status: report of two cases. Oral Surg Oral Med Oral Pathol Oral Radiol Endod 2007. 104:803-808

31. Schuster V, Hugle B, Tefs K: Plasminogen deficiency. J Thromb Haemost 2007, 5:2315-2322

32. Klammt J, Kobelt L, Aktas D, Durak I, Gokbuget A, Hughes Q, Irkec M, Kurtulus I, Lapi E, Mechoulam H, Mendoza-Londono R, Palumbo JS, Steitzer H, Tabbara KF, Ozbek Z, Pucci N, Sotomayor T, Sturm M, Drogies T, Ziegler M, Shuster V: Identification of three novel plasminogen (Plg) gene mutations in a series of 23 patients with low Plg activity. Thromb Haemost 2011, 105:454-460

33. Ploplis VA, Carmeliet P, Vazirzadeh S, Van Vlaenderen I, Moons L, Plow EF, Collen D: Effects of disruption of the plasminogen gene on thrombosis, growth, and health in mice. Circulation 1995, 92:25852593

34. Ny A, Leonardsson G, Hagglund AC, Hagglof P, Ploplis VA, Carmeliet $P$, Ny T: Ovulation in plasminogen-deficient mice. Endocrinology 1999, 140:5030-5035

35. Carmeliet $P$, Schoonjans L, Kieckens L, Ream B, Degen J, Bronson R, De Vos R, van den Oord JJ, Collen D, Mulligan RC: Physiological consequences of loss of plasminogen activator gene function in mice. Nature 1994, 368:419-424

36. Ny A, Nordstrom L, Carmeliet P, Ny T: Studies of mice lacking plasminogen activator gene function suggest that plasmin production prior to ovulation exceeds the amount needed for optimal ovulation efficiency. Eur J Biochem 1997, 244:487-493

37. Miao D, Scutt A: Histochemical localization of alkaline phosphatase activity in decalcified bone and cartilage. J Histochem Cytochem 2002, 50:333-340

38. Bezerra JA, Currier AR, Melin-Aldana H, Sabla G, Bugge TH, Kombrinck KW, Degen JL: Plasminogen activators direct reorganization of the liver lobule after acute injury. Am J Pathol 2001, 158:921-929

39. Lund LR, Green KA, Stoop AA, Ploug M, Almholt K, Lilla J, Nielsen BS Christensen IJ, Craik CS, Werb Z, Dano K, Romer J: Plasminogen activation independent of UPA and TPA maintains wound healing in gene-deficient mice. EMBO J 2006, 25:2686-2697

40. Beertsen W, Willenborg M, Everts V, Zirogianni A, Podschun R, Schroder B, Eskelinen EL, Saftig P: Impaired phagosomal maturation in neutrophils leads to periodontitis in lysosomal-associated membrane protein-2 knockout mice. J Immunol 2008, 180:475-482

41. Bugge TH, Flick MJ, Daugherty CC, Degen JL: Plasminogen deficiency causes severe thrombosis but is compatible with development and reproduction. Genes Dev 1995, 9:794-807

42. El-Darouti M, Zayed AA, El-Kamah GY, Mostafa MI: Ligneous conjunctivitis with oral mucous membrane involvement and decreased plasminogen level. Pediatr Dermatol 2009, 26:448-451

43. Toker H, Toker MI, Goze F, Turgut M, Yilmaz A: A ligneous periodontitis and conjunctival lesions in a patient with plasminogen deficiency. Oral Surg Oral Med Oral Pathol Oral Radiol Endod 2007, 103:e35-e38

44. Pierro VS, Vazquez-Sullca R, Vieira AS, Takiya CM, Carakushansky G, Feres-Filho EJ: Ligneous periodontitis and Ehlers-Danlos syndrome. J Periodontol 2006, 77:123-128

45. Baykul T, Bozkurt Y: Destructive membranous periodontal disease (ligneous periodontitis): a case report and 3 years follow-up. Br Dent J 2004, 197:467-468

46. Herren T, Burke TA, Jardi M, Felez J, Plow EF: Regulation of plasminogen binding to neutrophils. Blood 2001, 97:1070-1078

47. Price TH, Ochs HD, Gershoni-Baruch R, Harlan JM, Etzioni A: In vivo neutrophil and lymphocyte function studies in a patient with leukocyte adhesion deficiency type II. Blood 1994, 84:1635-1639

48. Niederman R, Westernoff T, Lee C, Mark LL, Kawashima N, UllmanCuller M, Dewhirst FE, Paster BJ, Wagner DD, Mayadas T, Hynes RO, Stashenko P: Infection-mediated early-onset periodontal disease in P/E-selectin-deficient mice. J Clin Periodontol 2001, 28:569-575

49. Bosshardt DD, Sculean A: Does periodontal tissue regeneration really work? Periodontol 2000 2009, 51:208-219

50. Castellino FJ, Ploplis VA: Structure and function of the plasminogen/ plasmin system. Thromb Haemost 2005, 93:647-654 
51. Garrett S, Bogle G: Periodontal regeneration: a review of flap management. Periodontol 2000 1993, 1:100-108

52. Pitaru S, Tal H, Soldinger M, Grosskopf A, Noff M: Partial regeneration of periodontal tissues using collagen barriers: initial observations in the canine. J Periodontol 1988, 59:380-386

53. Gottlow J, Nyman S, Lindhe J, Karring T, Wennstrom J: New attachment formation in the human periodontium by guided tissue regeneration: case reports. J Clin Periodontol 1986, 13:604-616

54. Caton J, Nyman S, Zander H: Histometric evaluation of periodontal surgery, II: connective tissue attachment levels after four regenerative procedures. J Clin Periodontol 1980, 7:224-231

55. Nyman S, Lindhe J, Karring T, Rylander H: New attachment following surgical treatment of human periodontal disease. J Clin Periodontol 1982, 9:290-296

56. Fernández-Tresguerres-Hernandez-Gil I, Alobera-Gracia MA, delCanto-Pingarrón M, Blanco-Jerez L: Physiological bases of bone regeneration, II: the remodeling process. Med Oral Patol Oral Cir Bucal 2006, 11:E151-E157

57. Daci E, Everts V, Torrekens S, Van Herck E, Tigchelaar-Gutterr W, Bouillon R, Carmeliet G: Increased bone formation in mice lacking plasminogen activators. J Bone Miner Res 2003, 18:1167-1176

58. Jaffe EA, Mosher DF: Synthesis of fibronectin by cultured human endothelial cells. J Exp Med 1978, 147:1779-1791

59. Timpl R, Rohde H, Robey PG, Rennard SI, Foidart JM, Martin GR: Laminin: a glycoprotein from basement membranes. J Biol Chem 1979, 254:9933-9937

60. Yee JA, Yan L, Dominguez JC, Allan EH, Martin TJ: Plasminogen-dependent activation of latent transforming growth factor beta (TGF beta) by growing cultures of osteoblast-like cells. J Cell Physiol 1993, 157:528-534

61. Allan EH, Zeheb R, Gelehrter TD, Heaton JH, Fukumoto S, Yee JA, Martin TJ: Transforming growth factor beta inhibits plasminogen ac- tivator (PA) activity and stimulates production of urokinase-type PA: PA inhibitor-1 mRNA, and protein in rat osteoblast-like cells. J Cell Physiol 1991, 149:34-43

62. Novak JF, Hayes JD, Nishimoto SK: Plasmin-mediated proteolysis of osteocalcin. J Bone Miner Res 1997, 12:1035-1042

63. Chenu C, Colucci S, Grano M, Zigrino P, Barattolo R, Zambonin G, Baldini N, Vergnaud P, Delmas PD, Zallone AZ: Osteocalcin induces chemotaxis, secretion of matrix proteins, and calcium-mediated intracellular signaling in human osteoclast-like cells. J Cell Biol 1994, 127:1149-1158

64. Bodine PV, Komm BS: Evidence that conditionally immortalized human osteoblasts express an osteocalcin receptor. Bone 1999, 25: $535-543$

65. Allan EH, Martin TJ: The plasminogen activator inhibitor system in bone cell function. Clin Orthop Relat Res 1995:54-63

66. Kurtulus I, Gokbuget A, Efeoglu A, Cintan S, Tefs K, Schuster V Scully C: Hypoplasminogenemia with ligneous periodontitis: a failed local therapeutic approach. J Periodontol 2007, 78:1164-1175

67. Fine G, Bauer K, Al-Mohaya M, Woo SB: Successful treatment of ligneous gingivitis with warfarin. Oral Surg Oral Med Oral Pathol Oral Radiol Endod 2009, 107:77-80

68. Schott D, Dempfle CE, Beck P, Liermann A, Mohr-Pennert A, Goldner M, Mehlem P, Azuma H, Schuster V, Mingers AM, Schwarz HP, Kramer MD: Therapy with a purified plasminogen concentrate in an infant with ligneous conjunctivitis and homozygous plasminogen deficiency. N Engl J Med 1998, 339:1679-1686

69. Watts P, Suresh P, Mezer E, Ells A, Albisetti M, Bajzar L, Marzinotto V, Andrew M, Massicotle P, Rootman D: Effective treatment of ligneous conjunctivitis with topical plasminogen. Am J Ophthalmol 2002, 133: $451-455$ 